\title{
THE IMPACT OF CLIMATE CHANGE ON THE YIELD OF SOME AGRICULTURAL CROPS
}

\author{
TOLBA S. ADLY', INAS EL-SAID SADIQ ${ }^{2}$ and M. M. M. ABD EL-AZIZ ${ }^{1}$
}

1. Fayoum University

2. Central Laboratory for Agricultural Climate, $A R C$, Giza

(Manuscript received 27 November 2016)

\begin{abstract}
A griculture is deeply affected by climate changes especially in developing countries. Some studies indicated that Wheat yield could be $18 \%$ less than usual, and Corn yield could be $19 \%$ less than usual in Egypt in case temperature rises one degree. This study aims at measuring the impact of climate change and climate variation on Wheat and Corn yield in Egypt. It used statistical methods and secondary data to achieve study objectives. The results showed that the main climate agricultural zones in Egypt are North Delta, South Delta and Middle Egypt, and Upper Egypt. The results indicated that yield is going down as we head South for both Wheat and Corn, Wheat yield reached 2.95, 2.89 , and 2.23 ton/feddan in the three zones respectively, while it reached 3.369, 3.047, and 2.389 ton/feddan respectively for cornThose yield variation were statistically significant, and Egypt society is loosing about L.E 1485 million yearly due to climate variation among climate zone. Hence, the climate effects should be deeply considered by policy makers. Finally the study recommends that more attention should be paid to the negative effects of climate changes, cereal breeders focus more on anti-heat stress varieties, and government should invest more in agricultural research and technology adaptation.
\end{abstract}


أثز التغيرات و التباينات المناخية على إنتاجية بعض الحاصلات الزراعية فى مصر

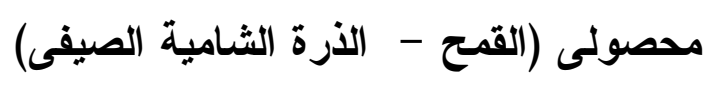

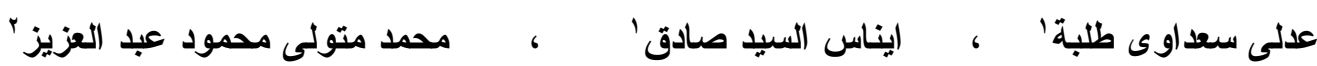

$$
\begin{aligned}
& \text { ا ـ . جامعة الفيوم } \\
& \text { r. المعدل المركزى للهناخ الزراعى لهي }
\end{aligned}
$$

مقدمة :

تؤدى التغيرات المناخية - خاصة ارتفاع درجات الحرارة - إلى عدد من الآتــار الســلبية

على المجتمعات والقطاعات الاقتصادية المختلفة، ومن أهم القطاعات التى تتأثز بهذه الظاهرة، قطاع

$$
\text { الزر اعة. }
$$

ويمكن القول أن ارتفاع درجات الحرارة يؤدى إلى عدد من الآثار المرتبطة بثـــل كبيـــر

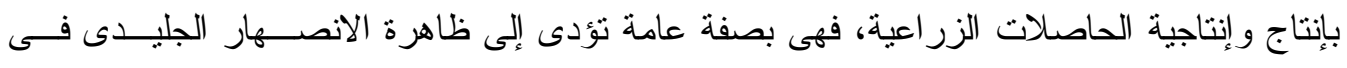

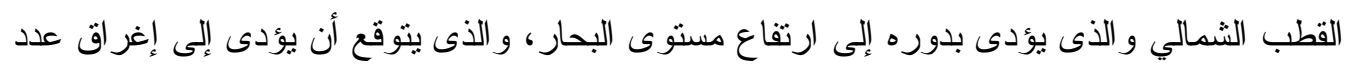

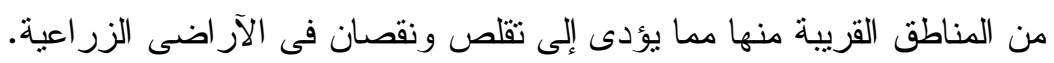

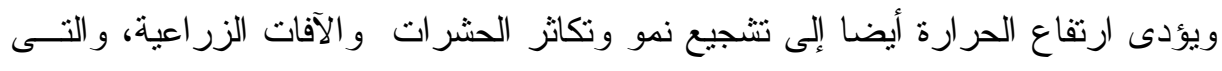

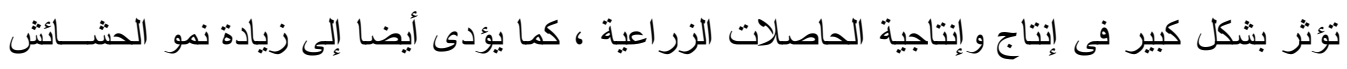

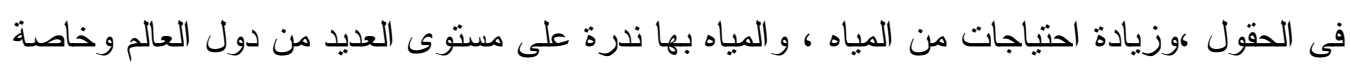
الدول العربية. - ماك. كنلك يؤدى ارتفاع درجات الحر ارة إلى انخفاض منوسطات إنتاج الوحدة المساحية من الحاصلات ما

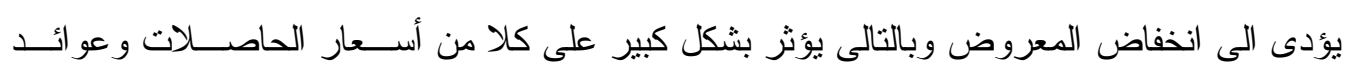

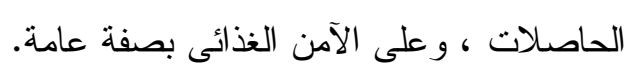

مشكلة الار اسة:

تتأثز الزراعة على مستوى العالم بالتغيرات المناخية، ويكون لتلك التغيرات المناخية أثز

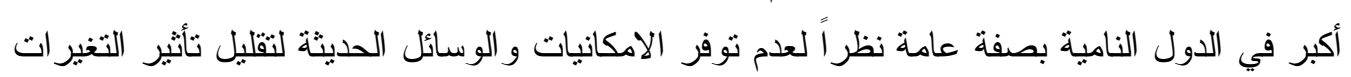

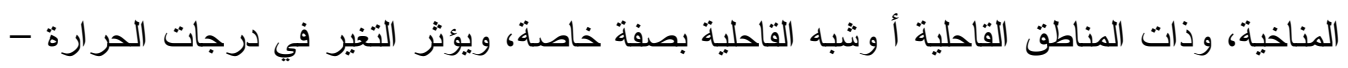
باعتباره العنصر المناخي الأهم- في طبيعة وكمية وقيمة الإنتاج الزر اعي بشكل كبير .

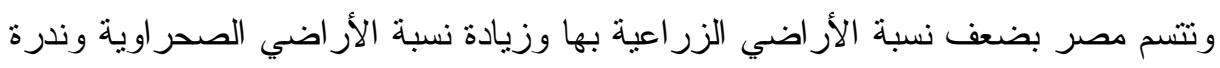
الأمطار و اعتمادها بنسبة تزيد عن 90\% علي مياه نهر النيل في الزراعة و الأنشطة البشرية

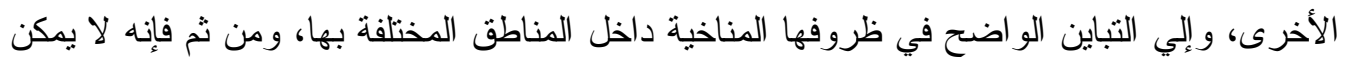

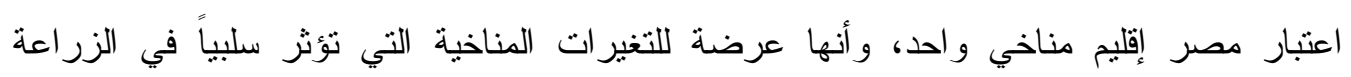

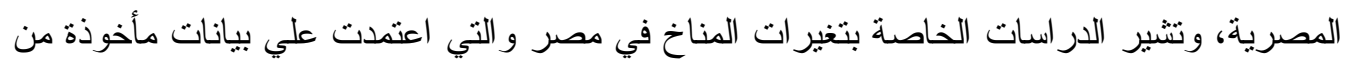

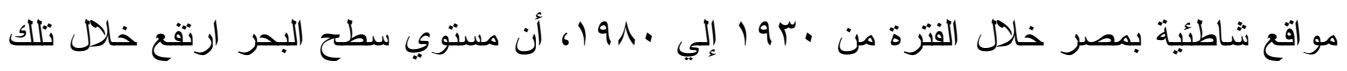


الفترة بنحو هب، 11 سم في مناطق رشيد ودمياط، و إلي حدوث زيادة تتز اوح بين منز ومترين في

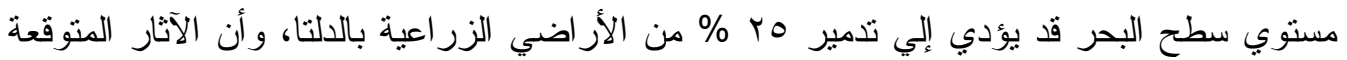

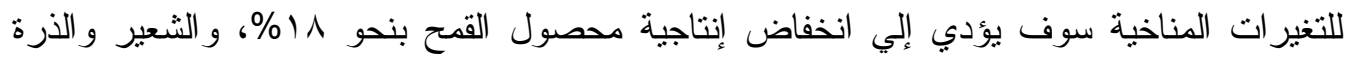
الثامية بنحو 19\%، والأرز بحو الي VI\%، و وأن ارتفاع درجات الحرارة سيؤدي إلي زيادة أعداد

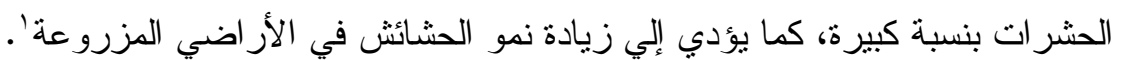

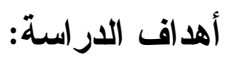
(1) شرح التقسيم الحالى للأقاليم المناخية الزر اعية فى مصر التهر (Y) تقدير أثز النباينات المناخية على انتاجية محصولى القمح والذرة الثامية الصيفى. (Y) تقدير أثز التغير ات المناخية على انتاجية محصولى القمح و الذرة الثنامية. (ع) تقدير الخسائر الإقتصادية الناجمة عن التغيرات المناخية.

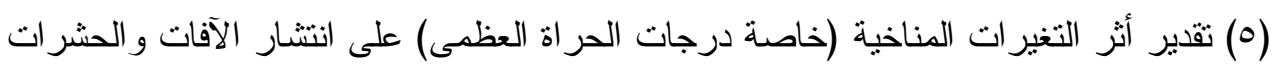
لمحصولى القمح و الذرة الثشامية الصيفى.

تعتمد الدر اسة علي أساليب البحث الوصفية و الكمية لتحقيق أهداف الدر اسة، كذلك تستند إلى القو اعد الاقتصادية والإحصائية المستمدة من كل من النظرية الاقتصادية، ونظرية الإحصاء، وتعتمد

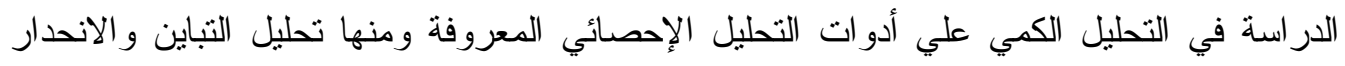
الخطى. نتائج الدر استة: أولاً: الأقسام المناخية لمصر من وجهة النظر الزراعيةّجا:

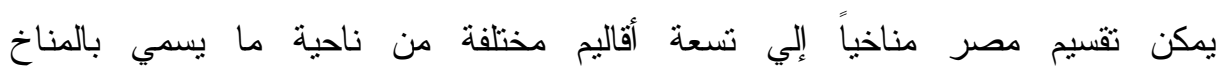
الإقليمي،Macro Climate وتلك بدورها تقسم إلي العديد من الأقسام من ناحية ما بسمي بالمناخ

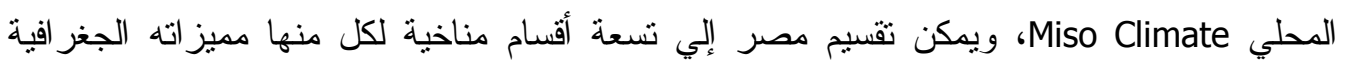

$$
\text { و المناخية و البيئية وهي: }
$$

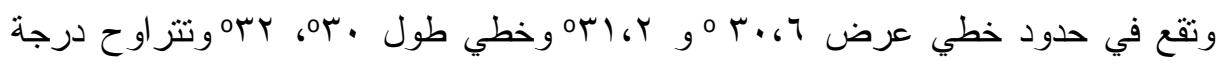

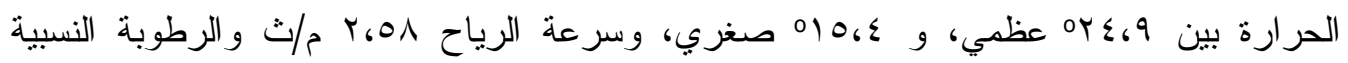
\%VY

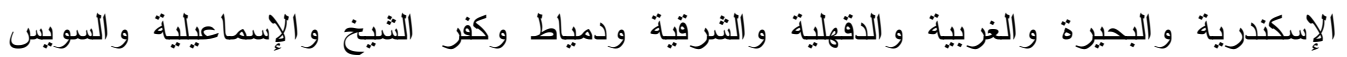

' أيمن أبو حديد" التغير ات المناخية المستقبلية و أثزر ها علي قطاع الزر اعة في مصر وكيفية مو اجهتها"- مركز المعلومات

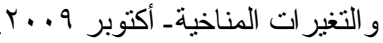

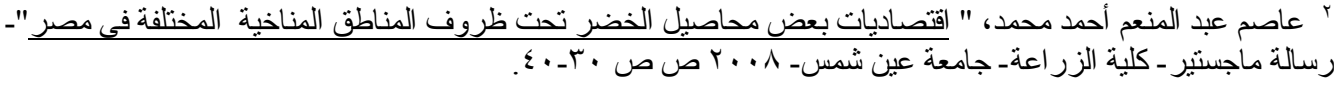




\section{ץ - جنوب الالتا ومصر الوسطي:}

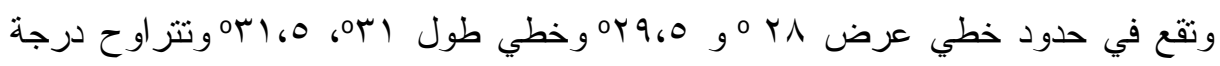

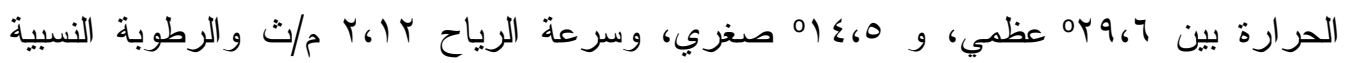
1\%، ومعدل البحر V،؛ مم/ يوم، ومعدل سقوط المطر ^،، • (مم/سنة وتضم سبع محافظات هي كالتالى المنوفية و القليوبية و القاهرة و الجيزة و الفيوم وبني سويف و المنيا. r- مصر العليا (الصعيد):

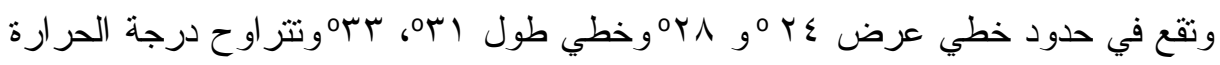

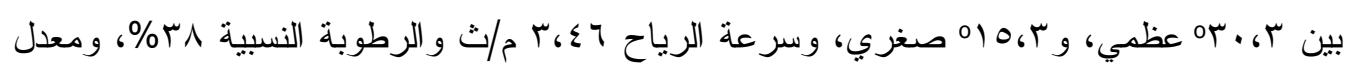
البحر 0،7 مم/ يوم، ومعدل سقوط المطر V، •مم/سنة ويضم هذا الإقليم محافظات أسيوط وسو هاج و الأقصر ، وقنا، و أسو ان.

وتعتبر هذه الأقاليم الثناثة هي الأقاليم الزراعية الرئيسية، وتعتمد قي ري أراضيها علي مياه نهر النيل، أما الأقاليم الأخرى فإنتاجها الزر اعي محدود، وتعتمد علي الأمطار أو المياه الجوفية في الري، وتلالك الأقاليم هي: ع- الساحل الثمالي الغربي 0- شمال سيناء 7- جنوب سيناء

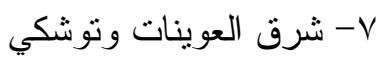
1- الو احات الداخلة و الخارجة 9- الو احات البحرية و الفر افرة

هذا وييين الجدول رقم (1) منوسطات درجات الحرارة العظمى الربع سنوية للأقاليم المناخية الزراعية الرئيسية الثلاثة وهي (شمال الدلتا، وجنوب الدلتا ومصر الوسطي، مصر العليا) بالإضافة الى اجمالى مصر ويمكن تجاوزاً اعتبار المتوسطات ربع السنوية هي متوسطات درجات

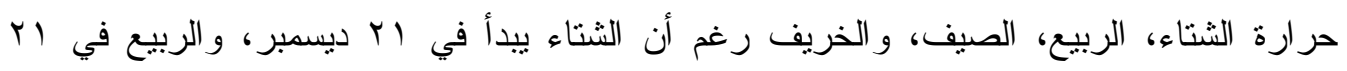

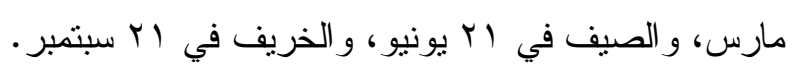
ويلاحظ وبصفة عامة أن متوسطات حرارة إقليم شمال الدلتا أقل من مثلتها في جنوب الدلتا ومصر الوسطي، والتي هي أقل من مثللتها في مصر العليا كما أن متوسط درجة حرارة إقليم شمال الالتا في كل الفصول أقل من متوسط الجمهورية بينما ترتفع درجات الحرارة في الإقليمين الثاني و الثالث عن متوسط الجمهورية. 


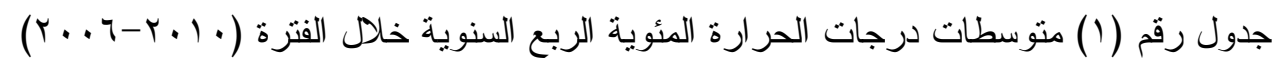
علي مستوي الأقاليم المناخية الزر اعية الرئيسية

\begin{tabular}{|c|c|c|c|c|c|c|c|c|c|c|c|c|c|c|c|c|}
\hline \multirow{2}{*}{ 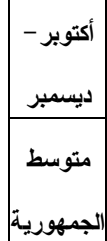 } & \multirow{2}{*}{ متوليو - أغسطس } & \multirow{2}{*}{ متونيو } & \multirow{2}{*}{ 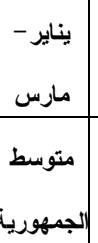 } & \multicolumn{3}{|c|}{ أكتوبر - ديسمبر } & \multicolumn{3}{|c|}{ يوليو - أغسطس } & \multicolumn{3}{|c|}{ إبريل - يونيو } & \multicolumn{3}{|c|}{ يناير - مارس } & \multirow{2}{*}{ السنوات } \\
\hline & & & & إقليم & $\begin{array}{l}\text { إقليم (ץ) } \\
\text { (ץ) }\end{array}$ & إقليم & $\begin{array}{l}\text { إقليم } \\
\text { (ץ) }\end{array}$ & $\begin{array}{l}\text { إقليم } \\
\text { (ץ) }\end{array}$ & إقليم & إقليم & $\begin{array}{l}\text { إقليم } \\
\text { (ץ) }\end{array}$ & إقليم & إقليم & إقليم & | إقليم & \\
\hline rq, r & ro.v & $r \leqslant, 7$ & r9.7 & $r_{6} \cdot$. & $r q, r$ & זт، & $\varepsilon 1, r$ & $r V_{6}$. & $r 1,1$ & $\varepsilon 1, r$ & חד, & $r q . V$ & Tr.t & $r \cdot ، v$ & $r \Lambda_{6} \wedge$ & r... \\
\hline$r \cdot \sigma r$ & $r \varepsilon_{0} r$ & r., & YA, & rT.O & $r \cdot . v$ & $r V_{6} V$ & $\varepsilon \cdot 9 q$ & $\left.r V_{6}\right)$ & ria.. & $\varepsilon r_{6}$. & $r \Lambda_{6} \tau$ & rro. & MI.9 & $r q_{6}$. & $r \leqslant \sigma V$ & $r \ldots v$ \\
\hline r..० & rr.q & ro,r & rY, T & $r \varepsilon_{0}$. & 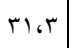 & YA، $\varepsilon$ & $\leqslant 1,$. & $r 4.0$ & $r . r T$ & $\leqslant 1,7$ & rA, r & $r_{6} \cdot$ & r.o & rv, & $r \leq 6 V$ & $r \ldots \wedge$ \\
\hline r., & ro,... & ro.r & rq، ६ & Tr.T & M. & YA, $Y$ & $\leqslant 1,6$ & rד، & $r \cdot r r$ & $\leqslant 1 ،$ A & m.,o & $r 9.9$ & Tr.V & $r q, r$ & r.,V & r...q \\
\hline rY, & ד. דוז & דו. & r1.9 & ro, 1 & rY,A & $r q, 7$ & $\varepsilon r_{G} V$ & $r_{\left.\lambda_{6}\right)}$ & ( A، & $\varepsilon Y_{6} T$ & r人, $\varepsilon$ & rr.T & ז4.. & rY.V & $r q, 1$ & r.l. \\
\hline
\end{tabular}

1- الأقاليم (1)، (Y)، (r) هي شمال الدلتا، وجنوب الدلتاومصر الوسطي، ومصر العليا

r- متوسطات الجمهورية تتضمن كل أقاليم مصر المناخية.

المصدر : جمعت وحسبت من وزارة الزر اعة واستصلاح الأر اضي، مركز البحوث الزر اعية المعمل المركزي للمناخ الزر اعي كبيانات غير منشورة.
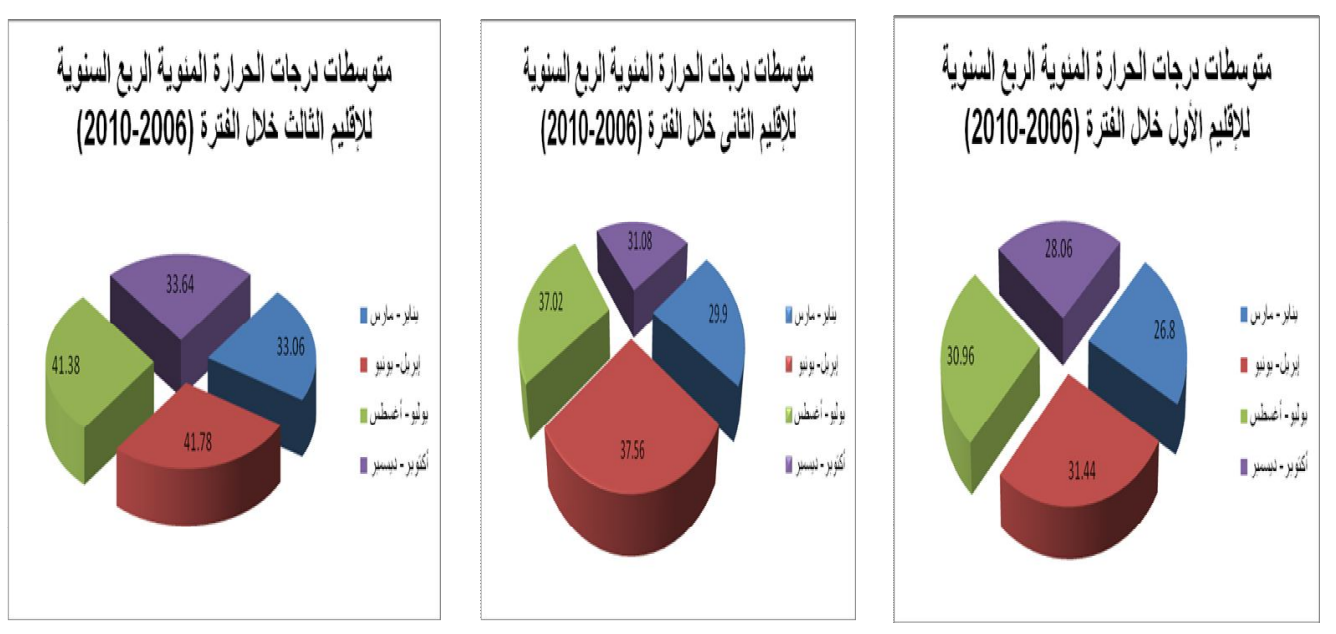

ولتأكيد كون الأقاليم الثلاثة أقاليم مناخية مختلفة أجري تحليل التباين في اتجاه واحد لكل ربع .سنة علي حدة، وتبين من نتائج التحليل ما يلي: (1) ربع السنة الأولي ( الثتاء تجاوزاً)

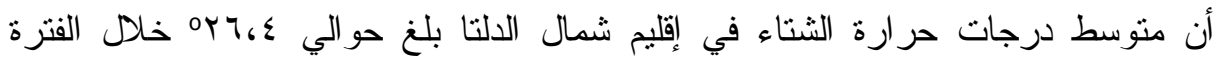

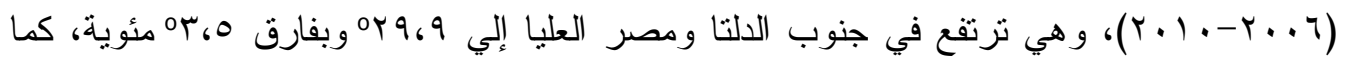

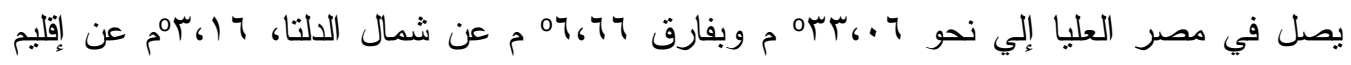
جنوب الالتا ومصر الوسطي، هذا ويشير الجدولين (r)، (r) إلي معنوية هذه الفروق بين 
المتوسطات مؤكدة علي كون الأقاليم الثلاثة مستقلة ومختلفة مناخياً، حيث بلغت قيمــــة ف

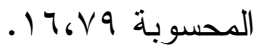
جدول رقم (ץ) منوسطات درجات الحر ارة العظمي الثشرية المئوية لفصول العام المختلفة

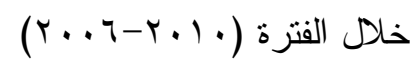

\begin{tabular}{|c|c|c|c|c|c|c|c|c|c|c|c|c|}
\hline \multicolumn{3}{|c|}{ الخريف } & \multicolumn{3}{|c|}{ الصيف } & \multicolumn{3}{|c|}{ الربيع } & \multicolumn{3}{|c|}{ الثتاء } & \multirow[b]{2}{*}{ الإقليم } \\
\hline SD & $\mathbf{M}$ & $\mathbf{N}$ & SD & $\mathbf{M}$ & $\mathbf{N}$ & SD & $\mathbf{M}$ & $\mathbf{N}$ & SD & $M$ & $\mathbf{N}$ & \\
\hline 1,171 & YA, . T & 。 & .071 & $r .697$ & 。 & $1.0 \varepsilon$ & r I. & 。 & I.AYO & YT، & 。 & شمال الالتا \\
\hline $1, r \cdot r$ & r।.. A & 。 & . 67. & $r Y_{6} . r$ & 。 & $1.1 \mathrm{~V}$ & $r V_{6} 07$ & 。 & 1,140 & $r q .9$ & 。 & ومصر الوسطي الدلتا \\
\hline 1,110 & Tr.TE & 。 & . vor & \&l.rی & 。 & . $r \leqslant 99$ & $\varepsilon 1 . \vee \wedge$ & 。 & $1 . V V T$ & rr..t & 。 & مصر \\
\hline
\end{tabular}

المصدر: جدول جمعت وحسبت من الجدول رقم (1)

جدول رقم (ץ) نتائج تحليل التباين لمتوسطات درجات الحرارة العظمي بين الأفاليم المناخية

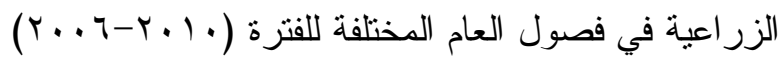

\begin{tabular}{|c|c|c|c|c|c|c|c|c|c|c|c|c|}
\hline \multicolumn{3}{|c|}{ الخريف } & \multicolumn{3}{|c|}{ الصيف } & \multicolumn{3}{|c|}{ الربيع } & \multicolumn{3}{|c|}{ الشتاء } & \\
\hline \multicolumn{3}{|c|}{ مصدر الخطأ } & \multicolumn{3}{|c|}{ مصدر الخطأ } & \multicolumn{3}{|c|}{ مصدر الخطأ } & \multicolumn{3}{|c|}{ مصدر الخطأ } & \\
\hline جملة & المشاهدات & المعاملات & جملة & المشاهدات & بين & جملة & المشاهدات & المعاملات & جملة & المشاهدات & المعاملات & \\
\hline $1 \leqslant$ & ir & r & $1 \leqslant$ & ir & r & $1 \leqslant$ & ir & r & $1 \leqslant$ & ir & $r$ & D.F \\
\hline $90,1 \mathrm{~V}$ & 18,10 & $V_{1} A_{6} \cdot r$ & rVq, & $0, \varepsilon$ & $v r_{6} \lambda$ & rNo,VT & $10, \leqslant T$ & $r V \cdot r r$ & 10.674 & $T \vee, r q$ & $99,11$. & SS \\
\hline- & $1, \varepsilon r$ & $r q, .1$ & - & $.6 \leq \leqslant 9$ & 154.9 & - & 1.59 & iro & - & $r, r$ & $\leqslant 9,00$ & MS \\
\hline - & - & KV.TQ & - & - & $r . \varepsilon, 90$ & - & - & 1.06 .9 & - & - & $\vee 9,17$ & $\mathbf{F}$ \\
\hline
\end{tabular}

(المصدر: جمعت وحسبت من الجدول رقم (1) (ץ) ربع السنة الثاني ( الربيع تجاوزاً)

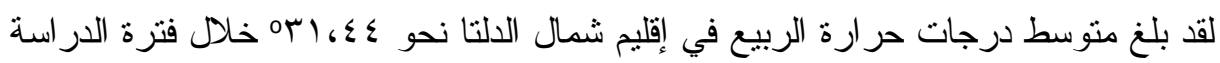

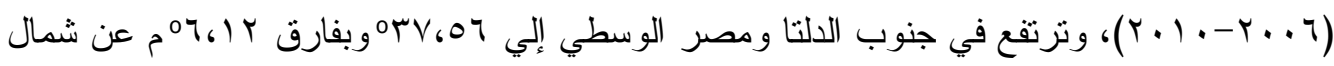

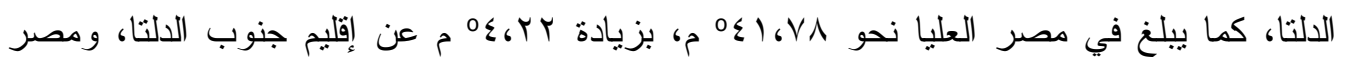
الوسطي، ونحو عاب، • إم عن شمال الدلتا.

هذا ولقد تأكدت معنوية هذه الفروق إحصائيا بإجر اء تحليل التباين وبلغت قيمة ف المحسوبة نحو 9 . 0, • 1 كما يتبين من الجدولين أرقام (r)، (r). 
لقد بلغ متوسط درجة الحرارة العظمي خلال شهور يوليو - سبتمبر نحو 97، ، به درجة

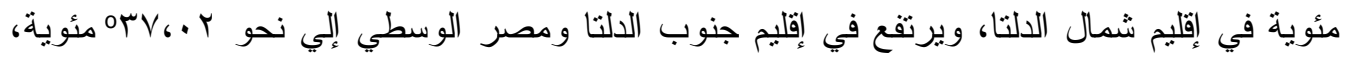

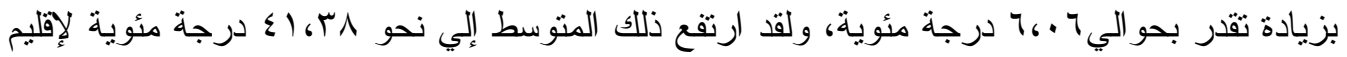

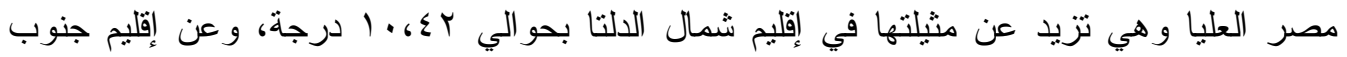

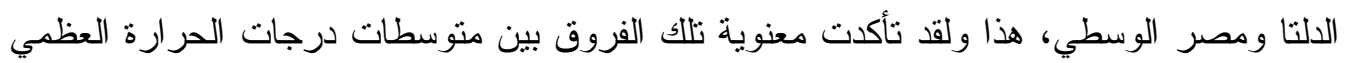
إحصائيا بإجر اء اختبار تحليل التباين حيث بلغت قيمة (ف) المحسوبة حو الى 90، ع ــ و وهذا ما يبينه

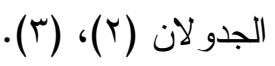

\section{(؛) ربع السنة الرابع ( الخريف تجاوزاً)}

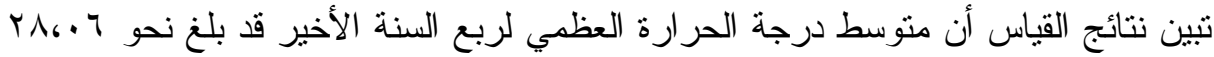

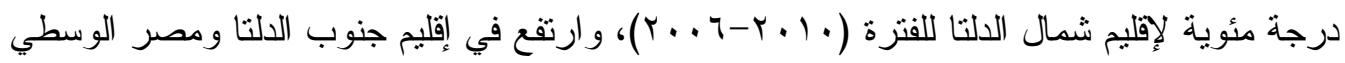

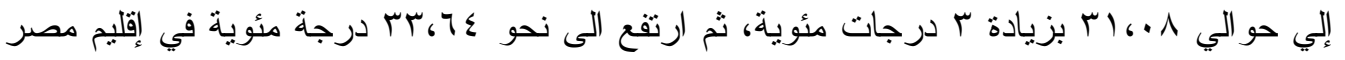

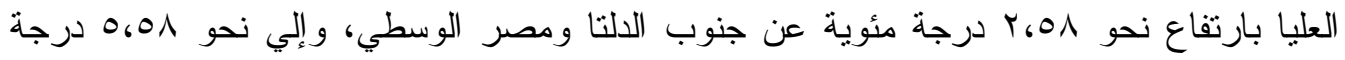
منؤية عن إقليم شمال الدلتا. هذا ويوضح الجدولان (r)، (r) تلك المتوسطات وكنلك معنوية الفروق بينها من خلال تحليل

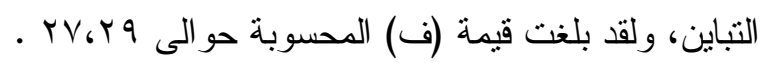
هذا ومن الو اضح أن الفروق في درجات الحرارة العظمي التي سادت في الأفاليم المناخية خلال فصول الثانية، كانت قليلة نسبيا في فصلي الثتاء والخريف ومرتفعة في فصلي الربيع و الصيف وأن هذه التباينات التي تعكس تغير ا مناخيا، تعكس في نفس الوقت اختلافا علي طبيعة

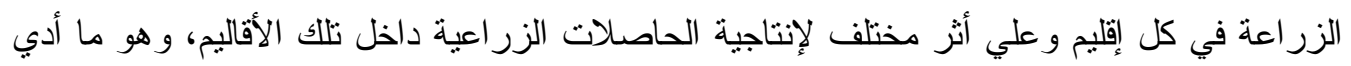

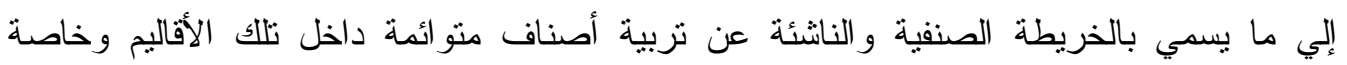
بالحاصلات، كما كان ذلك دافعا لمتخذ القرار في مركز البحوث الزر اعية لإنثاء محطات بحوث برثة

زر اعية إقليمية أهمها سخا والجميزة في شمال الدلتا، وسدسي في مصر الوسطي في مصر العانيا.

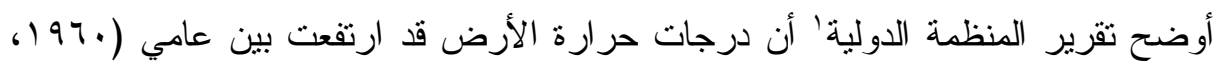

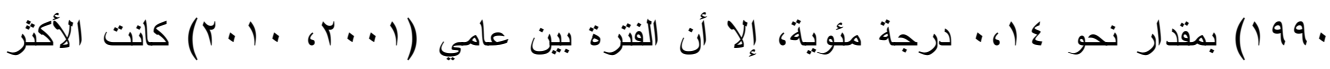

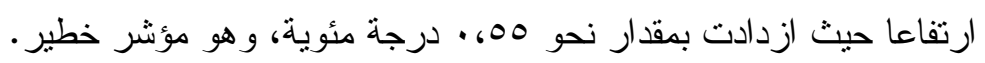

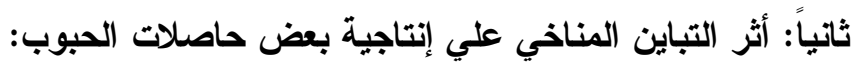

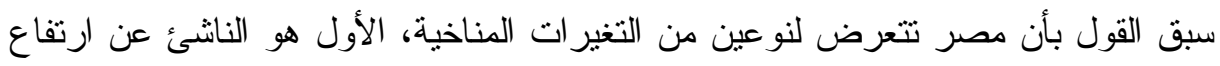

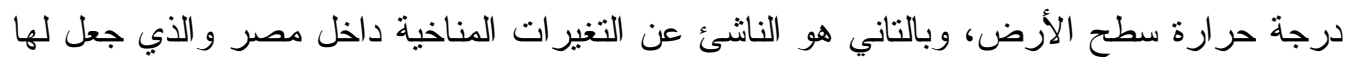

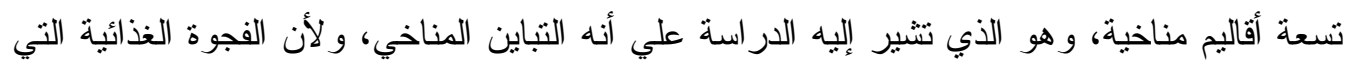
تعاني منها مصر معظمها في حاصلات الحبوب، وبالأخص محصولي القمح (الثتوي) والذرة 
الثامية (الصيفي) فإن هذا الجزء من الدراسة يقيس إحصائيا أثز التباينات المناخية علي إنتاجية هذين المحصولين الهامين، ثم قياس الأثز الاقتصادي الناشئ عن تلتك التباينات.

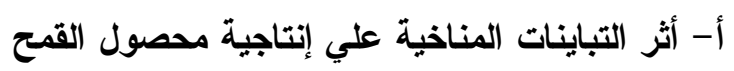
يشير الجدولين أرقام (ع)، (0) إلي متوسط إنتاجية محصول القمح لكل إقليم مناخي من الأقاليم

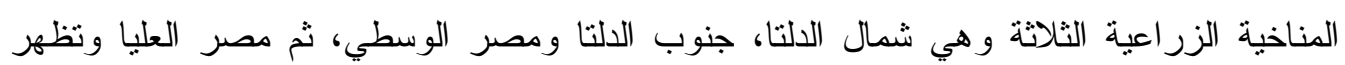

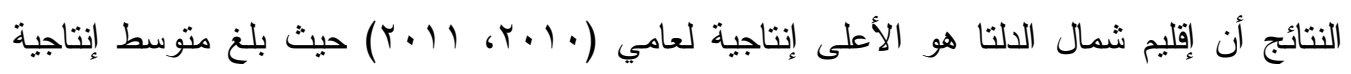

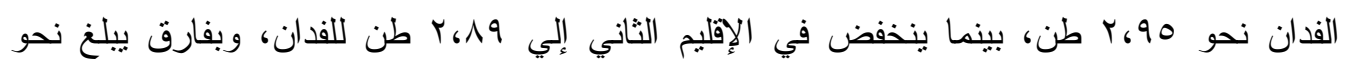

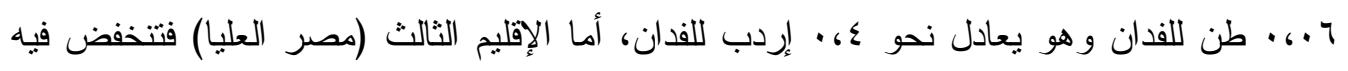

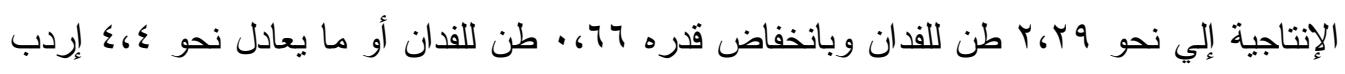

جدول رقم (ع) قياس منوسط إنتاجية الأقاليم المناخية لمحصول القمح

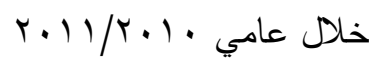

(طن/فدان)

\begin{tabular}{|c|c|c|c|}
\hline الالمر اف & متوسط الإنتاجية & عدد المشاهدات & الإقليم المناخي \\
\hline .0981 & r.90 & $r \cdot$ & شمال الدلتا \\
\hline .00 .99 & r.八9 & r & جنوب الدلتا ومصر الوسطي \\
\hline $.0 . \leqslant$. & $r_{6} Y_{9}$ & 1. & مصر العليا \\
\hline
\end{tabular}

المصدر: جمعت وحسبت من الجدول رقم (r) جدول رقم (0) نتائج تحليل التباين لإنتاجية الأفاليم المناخية من القمح

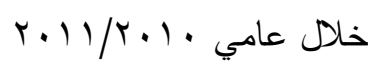

\begin{tabular}{|c|c|c|c|c|}
\hline قيمة ف & $\begin{array}{c}\text { متوسط مربع الخطأ } \\
\text { M.S }\end{array}$ & $\begin{array}{c}\text { مجموع مربع الخطأ } \\
\text { S.S }\end{array}$ & درجات الحرية & مصدر الخطأ \\
\hline \multirow[t]{3}{*}{$\varepsilon .97$} & $1,00 r$ & $\left.r_{6}\right) \cdot \varepsilon$ & r & بين المجموعات \\
\hline & rآ. & Ir.OY. & $\varepsilon$. & بين المشاهدات \\
\hline & & 10,7Y & $\leqslant r$ & الجملة \\
\hline
\end{tabular}

المصدر: جمعت وحسبت من الجدول رقم (r)

هذا ويشير جدول تحليل التباين أن هذه الفروق في إنتاجية الأقاليم المناخية من القمح معنوية إحصائيا، حيث بلغت قيمة (ف) المحسوبة نحو 97 ،؛ و وهي معنوية علي كافة مستويات المعنوية.

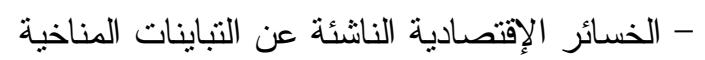

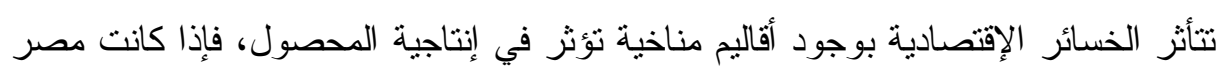
إقليما مناخيا واحدا لكانت إنتاجية الإقليم واحدة، ولارتفاع درجات الحرارة في الإقليم الثاني، وفي 
الإقليم الثالث عن الإقليم الأول انخفضت إنتاجية المحصول فيهما عن إقليم شمال الدلتا، وبفرض أن

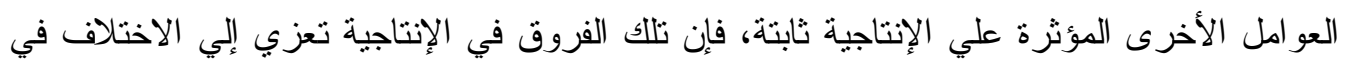
الظروف المناخية و التي تعكسها بشكل خاص درجة الحر ارة العظمي.

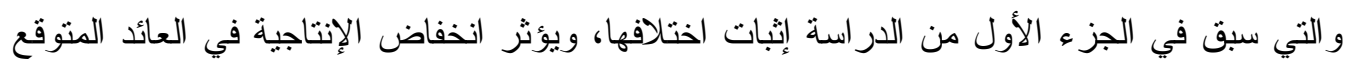
من المحصول في ضوء الأسعار المزرعية التي سادت خلال هذين العامين، ويشرح الجدولين أرقام

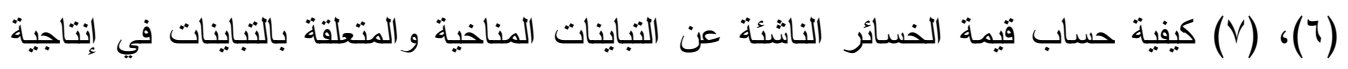
محصول القمح، وتبين النتائج أن جملة الخسائر الإقتصادية الناشئة عن تلائك التباينات المناخية

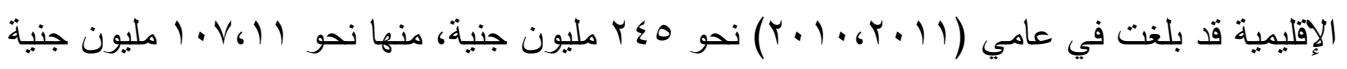

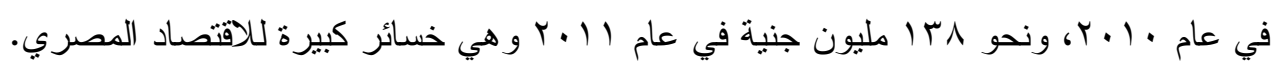
جدول رقم (†) حساب الخسائر الإقتصادية الناشئة عن التباينات المناخية

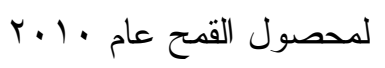

بالألف جنية

\begin{tabular}{|c|c|c|c|c|c|c|}
\hline قيمة الخسارة & جنية/طن المزرعي & الخسارة في الإتتاج & أل ألف فـاحة & طن/ قالإنتاجية & طن الإتتاجية & الأقاليم \\
\hline & & - & - & - & $r .90$ & شمال \\
\hline 110.0 .7 & TVY. & $\sum r_{6} r$ & $V .0$ & .67 & r.八9 & جنوب وسط \\
\hline 900.0 & & rol & Orr & ד77. & r.rq & مصر العليا \\
\hline 1.8 .11 & & & & & & الجملة \\
\hline
\end{tabular}

المصدر: جمعت وحسبت من الجدول رقم (ץ)

جدول رقم (V) الخسائر الإقتصادية الناشئة عن التباينات المناخية

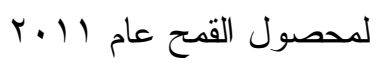

بالألف جنية

\begin{tabular}{|c|c|c|c|c|c|c|}
\hline قيمة الخسارة & جنية/طن المزرعي & الخسارة في الإتتاج & 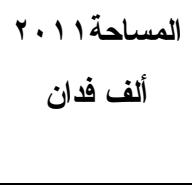 & الخسارة في & طن/ الإتاجية & الأقاليم \\
\hline & & - & - & - & $r .90$ & شمال \\
\hline $1 \leq 97$. & ror & $\leqslant r_{6} 0$ & $v .9$ & .67 & r.八9 & جنوب وسط \\
\hline IKYAEA & & $r \leqslant q$ & org & 774. & r.rq & مصر العليا \\
\hline 1 IrVA.A & & & & & & الجملة \\
\hline
\end{tabular}

المصدر: جمعت وحسبت من الجدول رقم (r)

ب- أثر التغير ات المناخية على منوسط إنتاج الفدان من القمح : 
أجريت محاولتين لقياس العلاقة بين متوسط إنتاج الفدان من القمح وعدد من المتغير ات المستقلة وهى

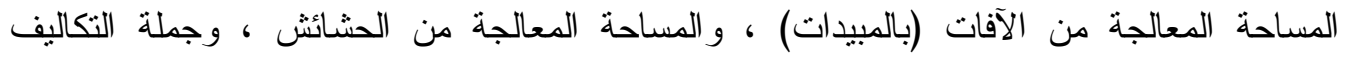
المتغيرة ودرجات الحرارة العظمى فى شهور يناير وفبر اير وشهر مارس ومتوسط درجة الحرارة

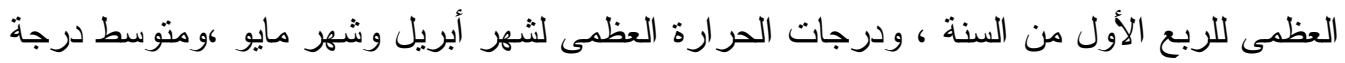

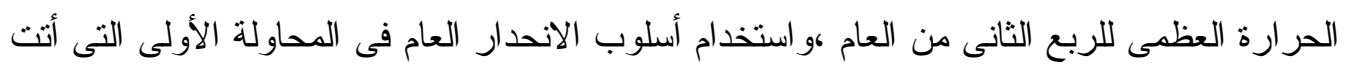
بنتائج منطقية من حيث الإشارة ، إلا أنها غير معنوية فى كل معاملات الانحدار وكذللك غير معنوية - النموذذج أما المحاولة الثانية فكانت باستخدام أسلوب الانحدار المتدرج .estep wize، ولنفس العوامل،

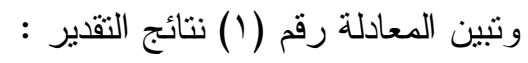

$$
\text { ص ص }
$$

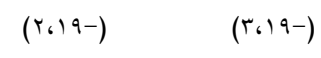

$$
.607=r
$$

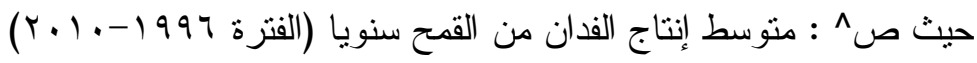

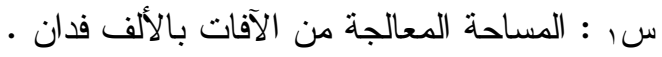

سr : منوسط درجة الحرارة العظمى الثهرى خلال الربع الأول من السنة (الشتاء)

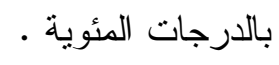

وتتشير نتائج المعادلة الى وجود علاقة عكسية بين الإنتاجية والمساحة المعالجة من الآفات ، باتل

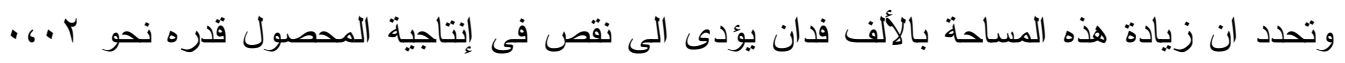

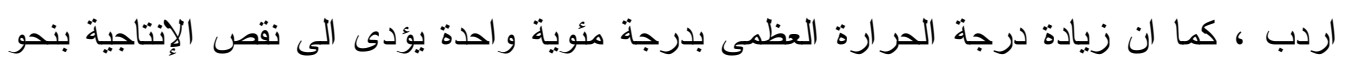

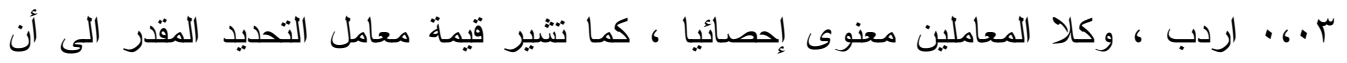

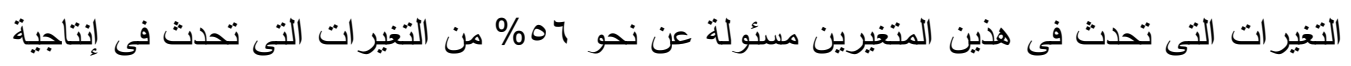

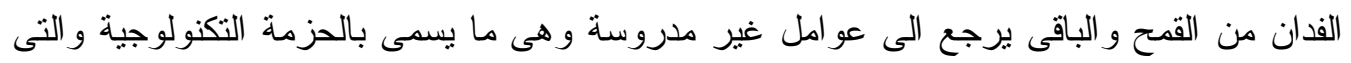

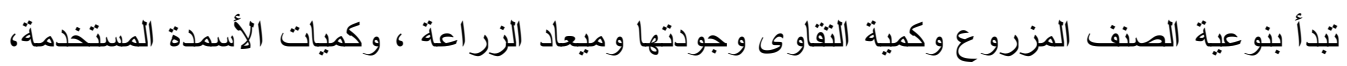
وكفاءة عملية الإدارة من مقاومة الآفات الحشائش ، و الى استخدام الميكنة فى عدد من العمليات بالإضافة الى الجوانب الاقتصادية المنمثلة فى حملة الإنفاق على المحصول ولى وعلى أسعار النواتج الته الرئيسية و الثانوية ،إلا أن هدف الدراسة كان بركز على الظواهر والعوامل المتعلقة بالتغيرات 


\section{الإنتاجية والمساحات المعالجة من الآفات والحشرات لمحصول القـح خلال الفترة (1996- 2010)}
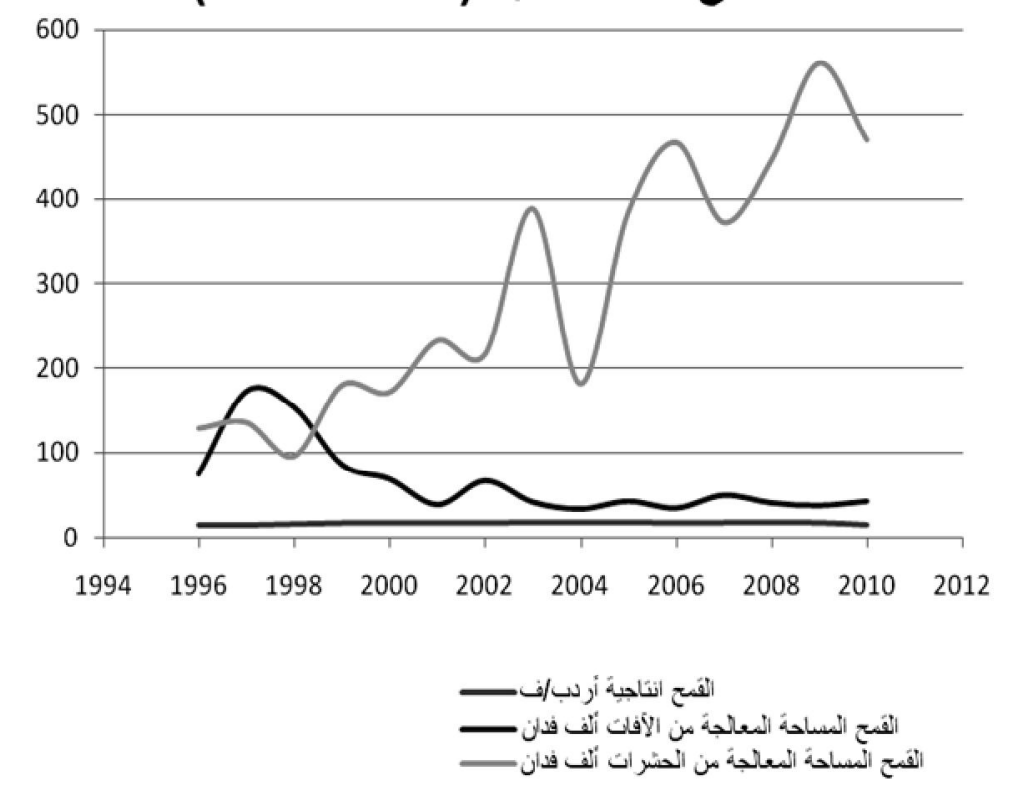

ج- أثز التغيرات المناخية على انتشار الآفات و الحشرات

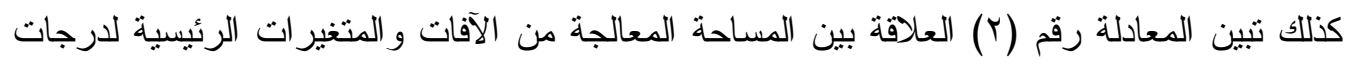

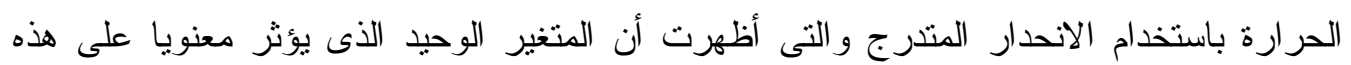

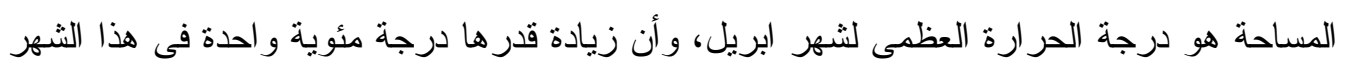

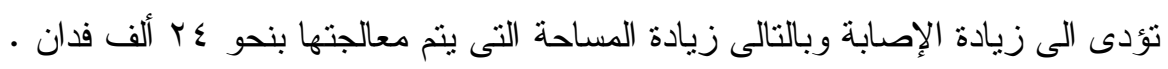

$\cdot{ }^{\prime} r=r$

حيث ص^ م : تقدير المساحة المعالجة من الآفات بالألف فدان .

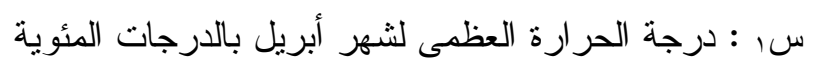

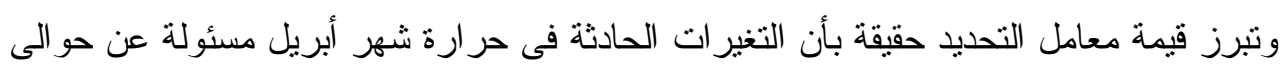

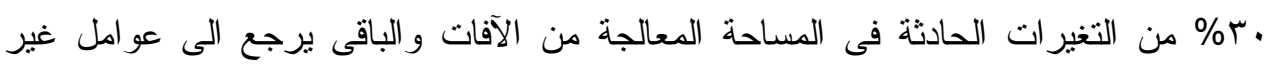

مثبته.

أما قياس العلاقة بين المساحة المعالجة من الحشائش ومتغيرات درجات الحرارة فلم تظهر

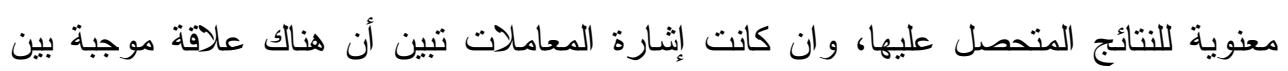
درجات حر ارة فبر اير ومارس و المساحة المعالجة من الحشائش ولكنها غير معنوية . 
ثالثاً: أثر التباينات المناخية علي إنتاجية محصول الذرة الثامية الصيفي يبين الجدول رقم (^) متوسط إنتاجية محصول الذرة الثامية للأقاليم المناخية الزراعية

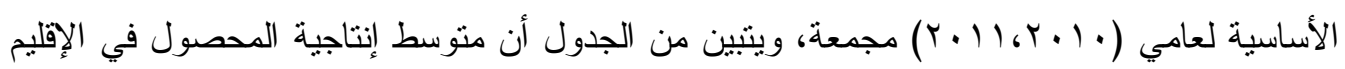

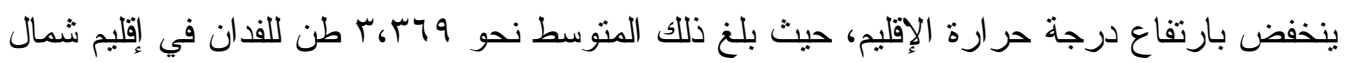

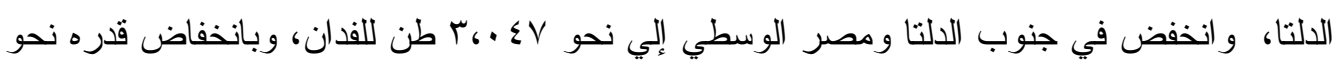

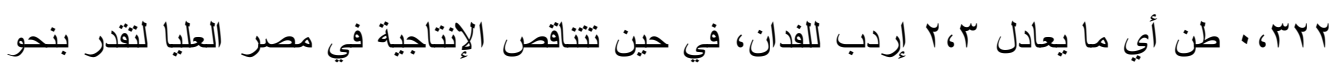

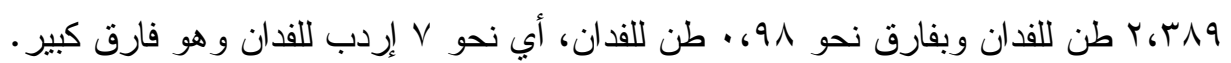
هذا ولقد تأكدت معنوية تلك الفروق إحصائيا في ضوء ون تحليل التباين المشروح في الجدول رقم (9) وارتفعت فيه قيمة (ف) المحسوبة إلي نحو ع (1، الم وهي معنوية علي كافة مستويات المعنوية.

جدول رقم (^) قياس منوسط إنتاجية الأقاليم المناخية لمحصول الذرة الثامي الصيفي

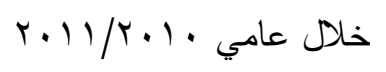

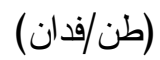

\begin{tabular}{|c|c|c|c|c|}
\hline قيمة ف & $\begin{array}{c}\text { متوسط مريع الخطأ } \\
\text { M.S }\end{array}$ & $\begin{array}{c}\text { مجموع مربع } \\
\text { S.S } \\
\text { S.S }\end{array}$ & $\begin{array}{c}\text { درجات الحرية } \\
\text { D.F }\end{array}$ & مصدر الخطأ \\
\hline $11,1 \leqslant$ & TG. T. & $7, \varepsilon .0$ & r & بين المعاملات \\
\hline & . TYAA & 11.619 & « & بين المشاهدات \\
\hline & & $11_{6} 19 \leqslant$ & $\varepsilon r$ & الجملة \\
\hline
\end{tabular}

المصدر: جمعت وحسبت من الجدول رقم (r)

جدول رقم (9) نتائج تحليل التباين لإنتاجية الأقاليم المناخية من الذرة الثامية

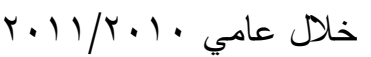

\begin{tabular}{|c|c|c|c|}
\hline الانحر اف & منوسط الإنتاجية & عدد المشاهدات & الإقليم المناخي \\
\hline אז & r. ז49 & $r$. & شمال الدلتا \\
\hline .67 .78 & $r_{6} . \leqslant V$ & $1 \varepsilon$ & جنوب الدلتاومصر الوسطي \\
\hline $.608 \cdot 1$ & r.r人q & 1. & مصر العليا \\
\hline
\end{tabular}

المصدر : جمعت وحسبت من الجدول رقم (r) الفيائ أ- تقدير الخسائر الإقتصادية الناشئة عن التباينات المناخية

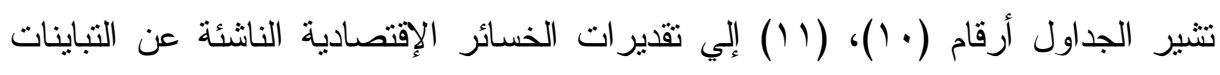

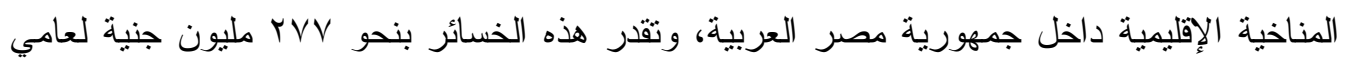

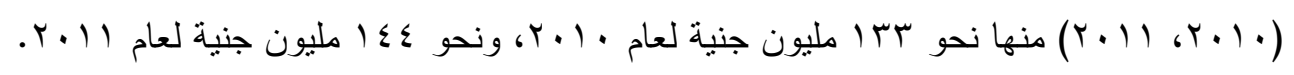


جدول رقم (• (1) حساب الخسائر الإقتصادية الناشئه عن التباينات المناخية

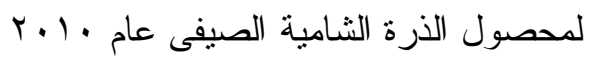

بالألف جنية

\begin{tabular}{|c|c|c|c|c|c|c|}
\hline قيمة الخسارة جنية & جنية/طن المزرعي & ألف الإتارة في & ألف ألف ف باحة & الخسارة في & طن/ فالإتاجية & الأقّاليم \\
\hline & & - & - & - & r.479 & شمال \\
\hline$T r \leqslant T 1$ & & rrA، & $V \leqslant 0$ & & $r_{6} . . \leqslant V$ & جنوب وسط \\
\hline 7.090 & & ATI,K & דוT & .991 & r.rیq & مصر العليا \\
\hline Tr.07 & & & & & & الجملة \\
\hline
\end{tabular}

المصدر: جمعت وحسبت من الجدول رقم (r)

جدول رقم (1') الخسائر الاقتصادية الناشئة عن التباينات المناخية

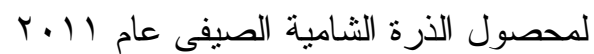

بالألف جنية

\begin{tabular}{|c|c|c|c|c|c|c|}
\hline قيمة الخسارة جنية & جنية/طن المزرعي & الخسارة في & 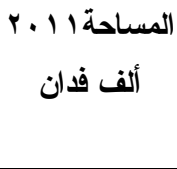 & الخسارة في & طن/ فالإتتاجية & الأقاليم \\
\hline & & - & - & - & r.479 & شمال \\
\hline $7 \Upsilon 7975$ & rTY & $r \varepsilon \cdot \sigma r r$ & Vol & r & $r_{6} . . \leqslant V$ & جنوب وسط \\
\hline $1 . \wedge \vee q$ & & $r \cdot 9$ & 510 & .691 & r.r人9 & مصر العليا \\
\hline $1 \leqslant r \wedge \leqslant r$ & & & & & & الجملة \\
\hline
\end{tabular}

المصدر : جمعت وحسبت من الجدول رقم (ץ) جملة الخسائر للمحصولين:

أن تقدير خسائر المجتمع نتيجة التباينات المناخية تشير إلي نحو 1، مليون جنية تنتاعي ضرورة التقكير في الاسنر اتجيات و السياسات و البرامج و الأساليب المناسبة لخفض هذئر هذه الخسائر وتقليلها إلي حدها الأدنى و الأساليب.

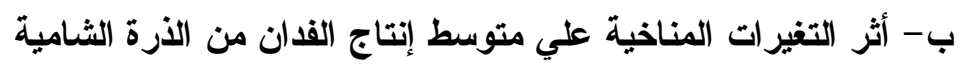
لدراسة أثز التغير ات المناخية علي إنتاجية محصول الذرة الثامية، نم تقدير العلاقة الإحصائية بين إنتاجية الفدان من الذرة الثامية، ودرجات الحر ارة العظمي في شهور (إبريل ومايو ويونيو ) ومتوسط لئه

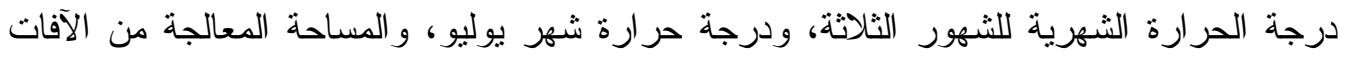
و المساحة المعالجة من الحشائش، وكان تقدير المعادلة كالتالي

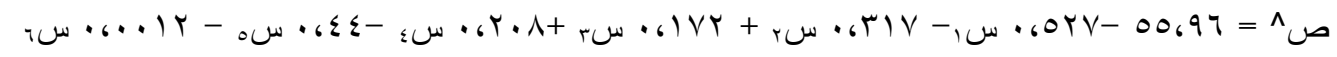
$\begin{array}{llllll}(.61 \xi) & (11 \gamma-) & (-.69) & (.61) & (-.619) & (-1.1)\end{array}$ 
صـ^: تقدير إنتاجية الفدان من الذرة الثامية بالإردب

س ا: درجة الحرارة العظمي المئوية لثهر إبريل

سץ: درجة الحر ارة العظمي المئوية لشهر مايو

سب: درجة الحر ارة العظمي المئوية لنشهر يونيو

س،: متوسط درجة الحر ارة العظمي المئوية الثهرية للثهور الثلاثة سه: درجة الحر ارة العظمي المئوية لنشهر يوليو س؟: المساحة المعالجة من الآفات بالآلف فدان سv: المساحة المعالجة من الحشائش بالآلف فدان

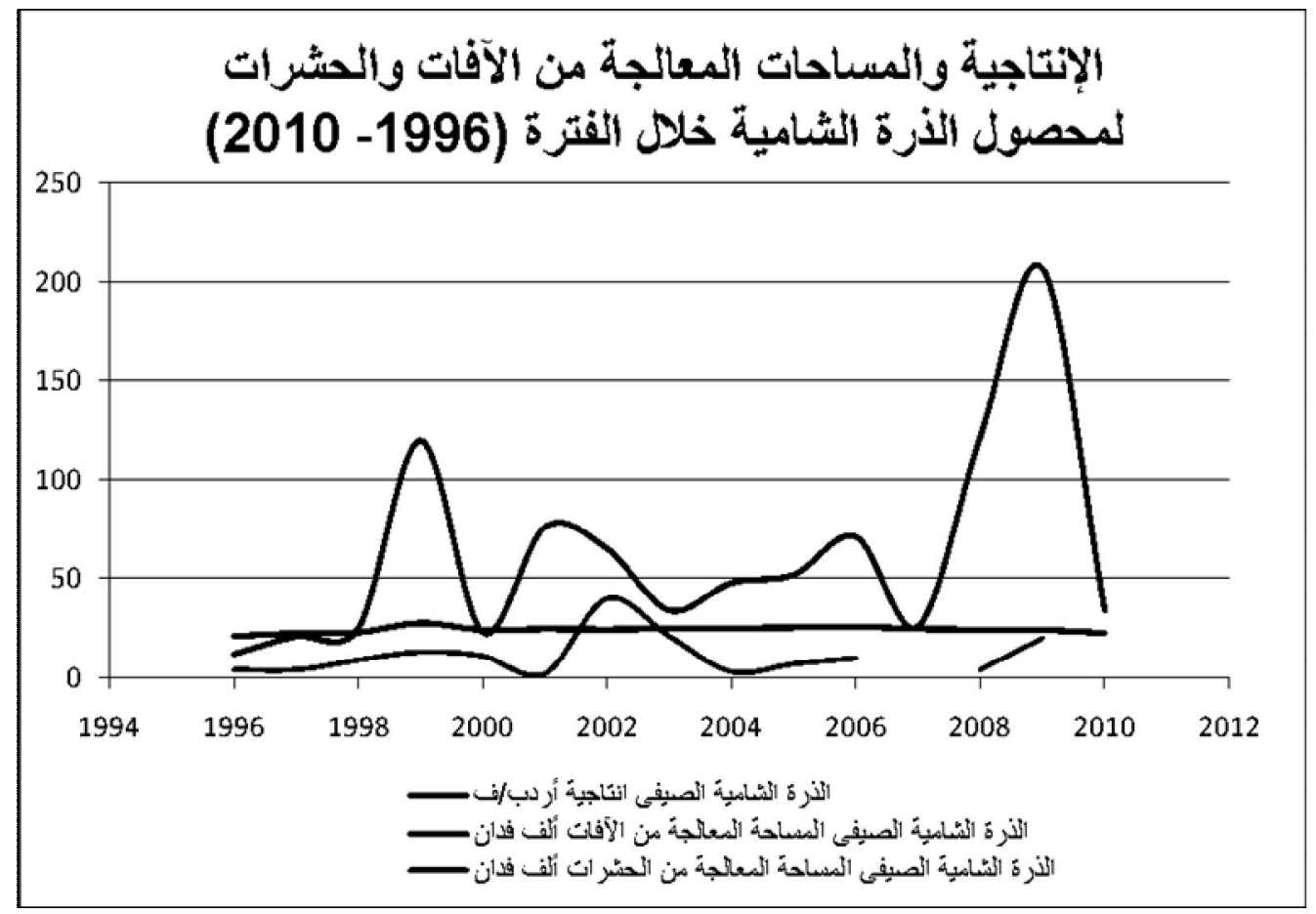

هذا ويتضح من المعادلة أن العلاقة بين درجات الحرارة العظمي في شهور (أبريل ومايو

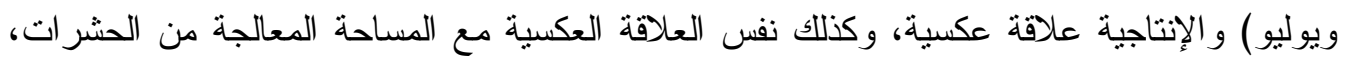
ولا يمكن الاستتاد إلي معاملات الانحدار المقدرة لتحديد تللك العلاقة الكمية بالأرقام لأن كافة مانة

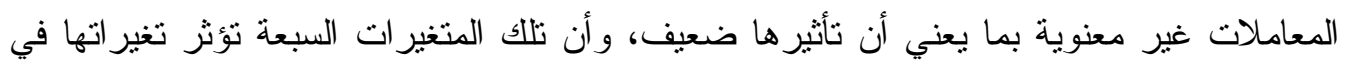

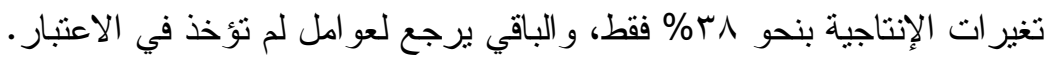

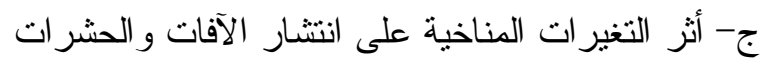

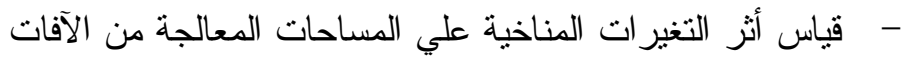

عند التقدير الإحصائي لهذه العلاقة لم تثبت معنوية أي من المتغيرات المناخية ( درجات الحرارة العظمي في شهور فترة مكث محصول الذرة الثامية)

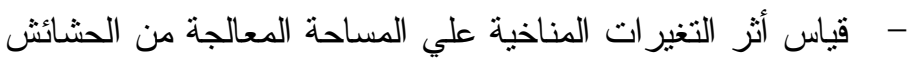




$$
\begin{aligned}
& \text { قدرة العلاقة الإحصائية باستخدام أسلوب الانحدار المتدرج وهى كالتالى: } \\
& \text { صـ }
\end{aligned}
$$

$$
.6 r V=r
$$

ص^^: تقدير المساحة المعالجة من الحشائش بالآلف فدان

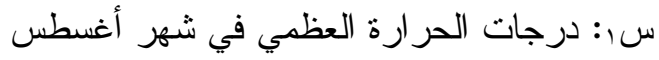

وتبين المعادلة أن زيادة درجة العظمي في شهر أغسطس بدرجة مئوية واحدة تؤدي إلي زيادة

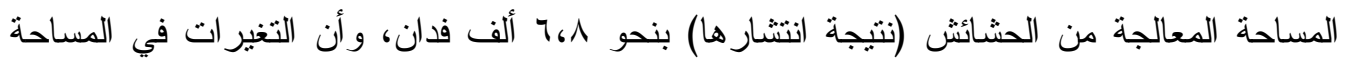

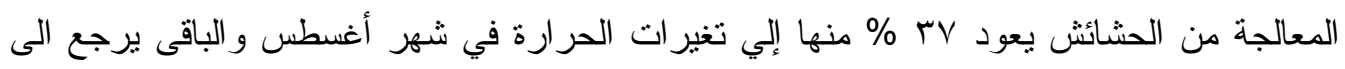
عو امل غير مدروسة.

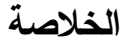

تخلص الدر اسة الحالية الى مجموعة من الحقائق التى يمكن ايجاز ها فى الآتى :

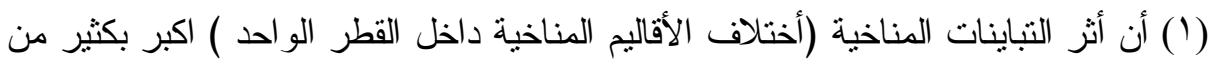

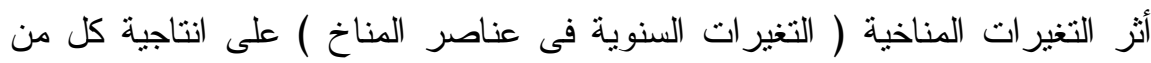
القمح والذرة وان استجابة محصول القمح للتغيرات المناخية اكبر من الاستجابة

$$
\text { للتغير ات المناخية لمحصول الذرة الثامية و التى تبدو أنها ضعيفة . }
$$

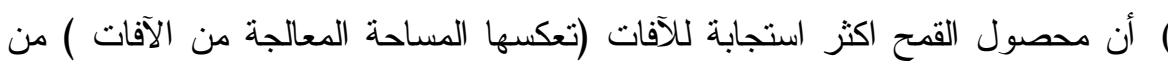

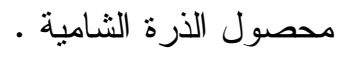

(r) أن المساحة المعالجة من الحشائش فى الذرة الثامية اكثر استجابة للتغيرات المناخية

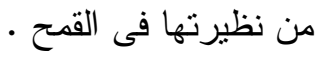

أن التباينات والتغير ات المناخية تسبب خسائر مادية كبيرة ، و أن الأستثمار فى تقليل

تلكك الخسائر سوف تكون له عو ائد جيدة على المزارغين و الاقتصاد القومى.

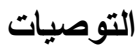

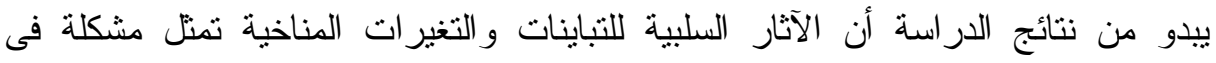
الأقتصاد الزراعى المصرى ، وتمثل خسارة فى محصولى الدراسة تقدر بالملايين من الجنيهات

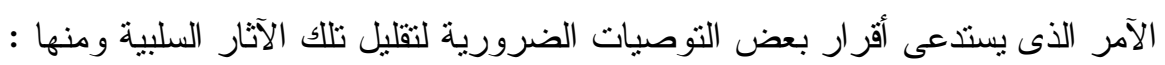

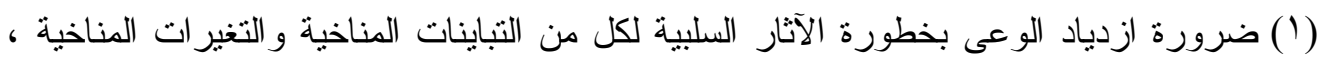

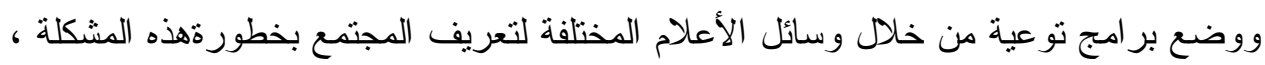
بالأضافة الى تضمين برامج الأرشاد الزر اعى للتوصيات المناسبة حول هذه المشكلة الاعلة 
(r) على مربى الحبوب محاولة زيادة الجهد فى استتباط الأصناف المقاومة للضغوط الحرارية Heat Stress ، و العمل على وضع الخرائط الصنفية الملائمة لمو اجهة التباينات المناخية بين الأقاليم الزر اعية المناخية.

(r) و على المربين ايضاً ادر اج قيمة التغيرات المرتبطة بالمو اسم الزر اعية بحيث يمكن النظر فى لرع تغير مو اعيد الزر اعة و الحصاد بما يتتاسب مع التغير ات المناخية الموسمية. (§) ضرورة البحث عن الأساليب التكنولوجية المناسبة المساعدة فى تخفيف آثز التغيرات و التباينات المناخية، وكذلك زر اعة الأسوار الثجرية لتخفيف آثر الحرارة وتقليل فاقد المياه الناشئ عن التبخر عند ارتفاع درجات الحرارة . 


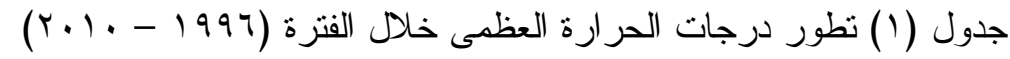

\begin{tabular}{|c|c|c|c|c|c|c|c|c|c|c|c|c|c|c|c|c|}
\hline الرابع & ديسمبر & نوفمبر & أكتوبر & الثالث & سبتمبر & أغسطس & يوليو & الثانى & يونيو & مايو & ابريل & الأول & مارس & فبر اير & يناير & السنوات \\
\hline 29.65 & 25.88 & 29.05 & 34.03 & 35.45 & 38.30 & 34.07 & 33,96 & 35,45 & 32,74 & 38,40 & 35,21 & 28,83 & 31,42 & 28,94 & 26,15 & 1997 \\
\hline 30,11 & 26,96 & 29,24 & 34,12 & 34,31 & 33,27 & 34,26 & 35,41 & 35,89 & 36,23 & 34,59 & 36,86 & 26,92 & 29,35 & 24,25 & 27,15 & $199 \mathrm{~V}$ \\
\hline 30,59 & 27,68 & 28,87 & 35,23 & 35,76 & 36,49 & 35,37 & 35,44 & 36,49 & 35,10 & 37,28 & 37,11 & 27,70 & 30,95 & 27,75 & 24,41 & 1991 \\
\hline 29,59 & 26,72 & 28,39 & 33,65 & 35,46 & 35,60 & 35,11 & 35,68 & 35,31 & 34,02 & 35,73 & 36,19 & 26,53 & 30,34 & 25,09 & 24,15 & 1999 \\
\hline 28,58 & 25,76 & 27,90 & 32,08 & 35,16 & 34,70 & 34,85 & 35,92 & 34,13 & 32,94 & 34,19 & 35,28 & 25,35 & 29,74 & 22,42 & 23,89 & r... \\
\hline 29,03 & 26,07 & 29,45 & 31,57 & 34,81 & 34,57 & 36,08 & 33,76 & 35,80 & 34,15 & 37,59 & 35,66 & 29,35 & 33,37 & 29,01 & 25,67 & $r \ldots l$ \\
\hline 30,43 & 26,89 & 29,68 & 34,71 & 37,04 & 36,56 & 36,96 & 37,61 & 34,77 & 35,08 & 33,77 & 35,45 & 27,84 & 31,51 & 28,46 & 23,56 & $r \ldots r$ \\
\hline 31,68 & 28,02 & 32,33 & 34,68 & 34,71 & 35,94 & 34,34 & 33,85 & 36,49 & 34,05 & 38,53 & 36,90 & 28,51 & 29,70 & 28,10 & 27,72 & $r \ldots r$ \\
\hline 30,26 & 25,90 & 30,91 & 33,97 & 35,56 & 36,20 & 34,33 & 36,15 & 35,73 & 35,72 & 37,71 & 33,77 & 30,36 & 33,99 & 31,42 & 25,67 & $r \ldots \varepsilon$ \\
\hline 31,80 & 30,42 & 30,62 & 34,36 & 35,14 & 35,34 & 35,30 & 34,78 & 34,71 & 34,48 & 34,01 & 35,64 & 30,42 & 32,07 & 30,38 & 28,80 & $r \ldots o$ \\
\hline 29,26 & 23,92 & 29,13 & 34,72 & 35,67 & 37,76 & 36,09 & 33,17 & 34,61 & 35,14 & 33,83 & 34,88 & 29,56 & 31,84 & 30,26 & 26,57 & $r \ldots r$ \\
\hline 30,24 & 25,61 & 32,01 & 33,10 & 34,22 & 33,46 & 34,37 & 34,83 & 36,08 & 37,33 & 36,29 & 34,64 & 28,05 & 31,42 & 27,50 & 25,24 & $r \ldots v$ \\
\hline 30,55 & 28,00 & 29,40 & 34,26 & 33,89 & 34,99 & 33,94 & 32,74 & 35,17 & 35,42 & 33,30 & 36,79 & 27,29 & 34,37 & 24,66 & 22,84 & $r \ldots \lambda$ \\
\hline 31,13 & 27,34 & 30,54 & 35,52 & 35,04 & 35,87 & 34,17 & 35,06 & 35,29 & 35,50 & 35,97 & 34,40 & 29,36 & 32,36 & 28,62 & 27,09 & $r \ldots q$ \\
\hline 32,28 & 28,05 & 31,71 & 37,08 & 36,58 & 36,69 & 36,57 & 36,48 & 36,57 & 37,88 & 37,52 & 34,31 & 31,94 & 35,23 & 31,82 & 28,75 & r.l. \\
\hline
\end{tabular}




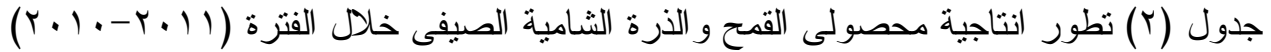

\begin{tabular}{|c|c|c|c|c|c|}
\hline \multicolumn{2}{|c|}{ انتاجية الذرة الثامية الصيفى } & \multicolumn{2}{|c|}{ انتاجية القمح } & \multirow{2}{*}{ المحافظات } & \multirow{2}{*}{ الأقاليم } \\
\hline$r .11$ & $r \cdot 1$. & $r .11$ & $r \cdot 1$. & & \\
\hline$r_{6} T_{1}$ & r.IV & rGtr & $r_{6} \leqslant 0$ & الأسكندرية & \multirow{10}{*}{ شمال الدلتا } \\
\hline T.VT & r.7) & $r_{6} v \leq$ & r.7T & البحيرة & \\
\hline r.vi & r.TV & r.vi & r.7 $\varepsilon$ & الغربية & \\
\hline r.VT & rovo & $r_{6} v \varepsilon$ & r.00 & كفر الثيخ & \\
\hline r.90 & $\varepsilon$ & 1.90 & r.o & الدقهلية & \\
\hline r.77 & r.71 & r.TV & T.to & دمياط & \\
\hline r.tV & TGYA & rGTV & T.TY & الثرقية & \\
\hline r.lV & r.91 & r.11 & $r_{6} \varepsilon$ & الإسماعيلية & \\
\hline$r_{6} \leqslant r$ & $r_{6} T_{1}$ & r.os & $\left.r_{6}\right) 1$ & بور سعيد & \\
\hline T.TT & $\left.r_{6} \wedge\right)$ & rGTV & T.TY & السويس & \\
\hline r.ro & r.VT & r.to & $r_{6} 0$ & القليو بية & \multirow{7}{*}{ ووسط مصر الدلتا } \\
\hline$\varepsilon_{6} \cdot V$ & r.VT & $\varepsilon_{6} \cdot V$ & T.VT & المنوفية & \\
\hline r.90 & $1 . V A$ & r.9 & $r_{6} \leqslant \Lambda$ & القاهرة & \\
\hline r.T & r.Vq & r.7 & r.OT & الجيزة & \\
\hline r.77 & r.T & T.TV & r.tT & الفيوم & \\
\hline Y.AV & r.T & Y.AV & T.TN & بنى سويف & \\
\hline r.11 & r.八9 & 1619 & r.7) & المنيا & \\
\hline r.91 & r.71 & r.91 & r.TV & أسبوط & \multirow{5}{*}{ مصر العليا } \\
\hline T.TT & r.7E & TGTr & r. & سو هاج & \\
\hline $16 V V$ & $16 \mathrm{VT}$ & $16 \mathrm{VT}$ & r.T & قنا & \\
\hline r.rT & 1.79 & T.TY & r & الأقصر & \\
\hline$r_{6} \leqslant \varepsilon$ & 1.91 & $r_{6} \leqslant 0$ & 1.9 & أسو ان & \\
\hline
\end{tabular}

المصدر : وز ارة الزر اعة واستصلاح الأراضى - قطاع الثئون الإقتصادية- نشرات الإحصائيات

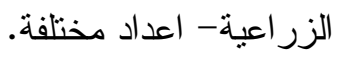


جدول (ץ) الإنتاجية و المساحات المعالجة من الآفات و الحشر ات للحصولى القمح و الذرة الثشامية

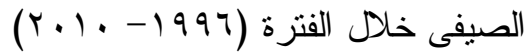

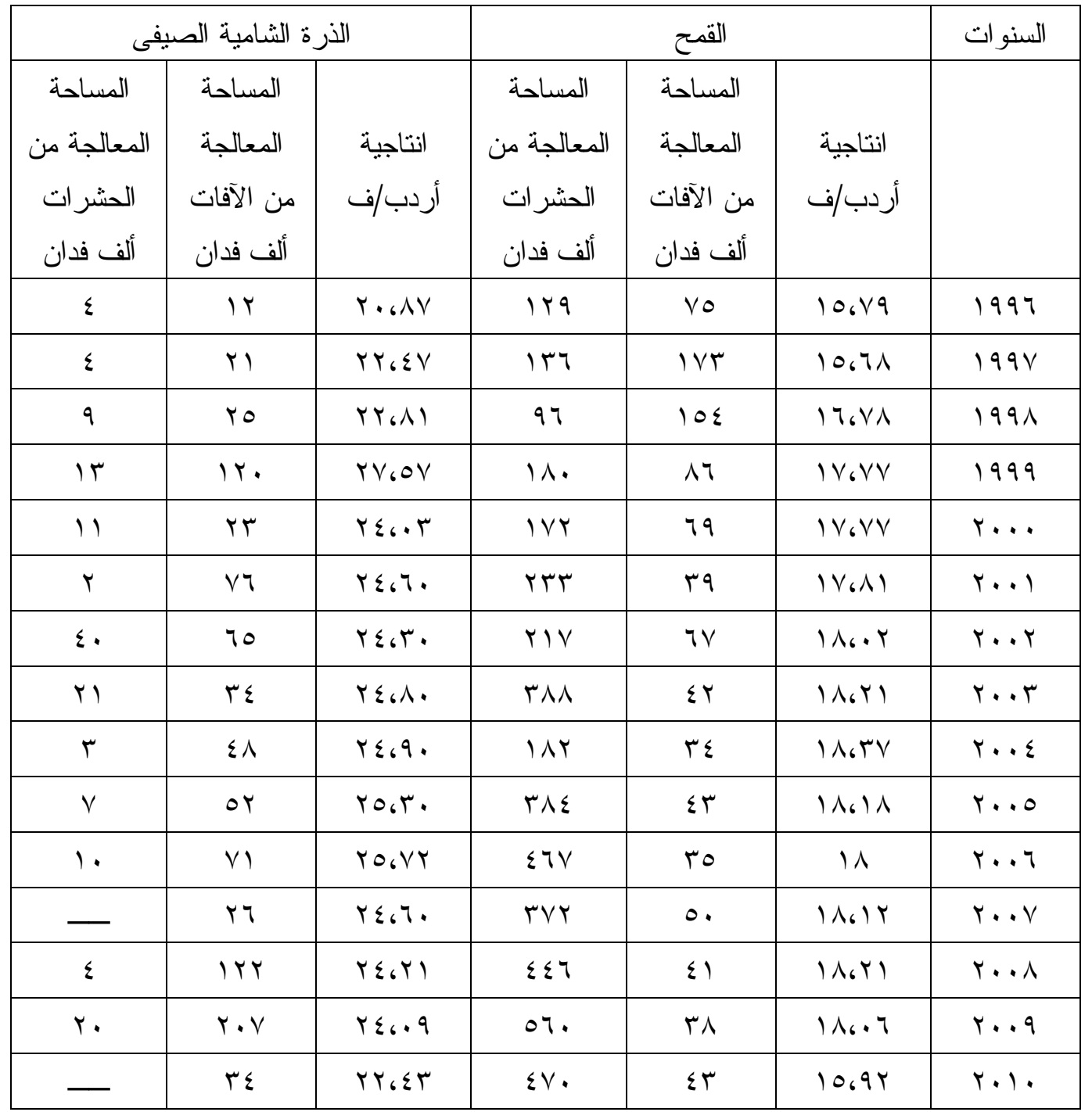

المصدر: وزارة الزراعة واستصلاح الأر اضى- قطاع الثنئون الاقتصادية- نشرات الإحصاءات الزر اعية- أعداد مختلفة. المساحة المعالجة: وزارة الزر اعة واستصلاح الأراضى- نشرات الإدارة العامة لمكافحة الآفات

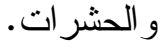




\section{الملخص}

تتأثز الزر اعة فى أى مكان فى العالم بالتغيرات المناخية ويكون لتلك التغيرات المناخية أثر

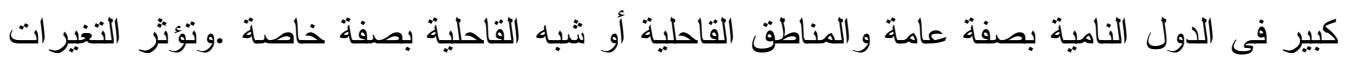

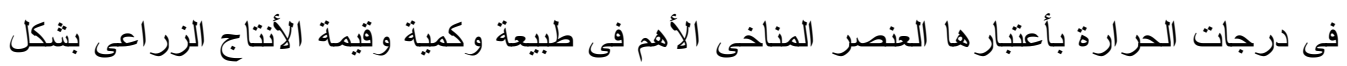

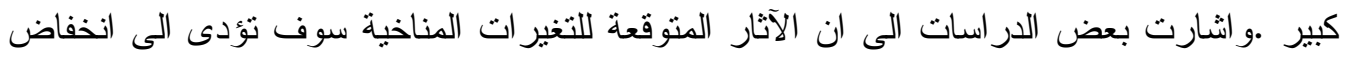

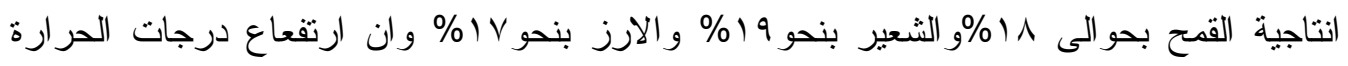

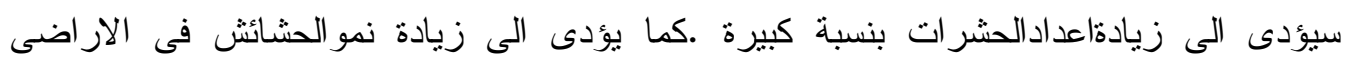
المزرو عة.

وتستهدف الدراسة التعرف على خصائص الاقاليم المناخية المختلفة ـ لكل منها مميز اتة

\section{الجغر افية و المناخية و البيئية .}

وقد نوصلت الدراسة من خلال دراسة الاقاليم المناخية الى ان منوسط انتاجية محصول

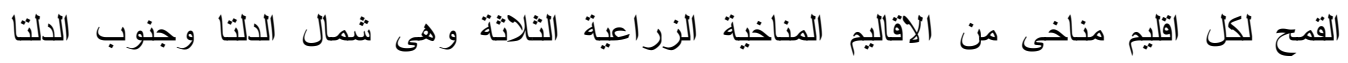

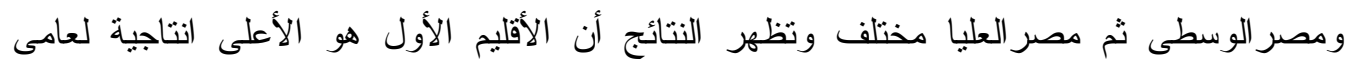

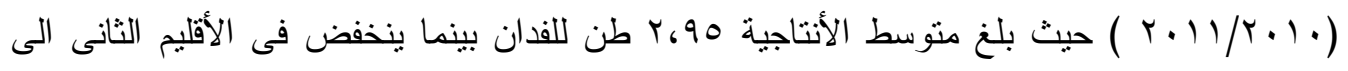

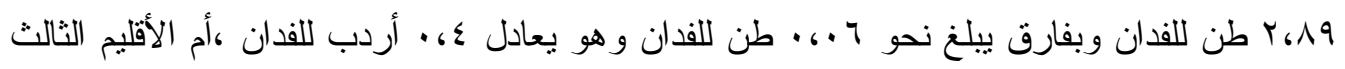

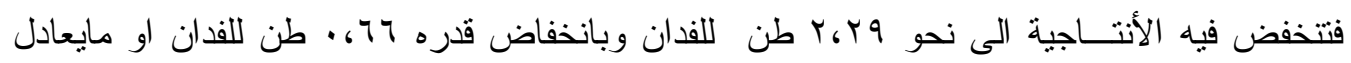
نحو ء،ء أردب للفدان ويشير تحليل التباين أن هذه الفروق فى انتاجية الأقاليم المناخية من القمح

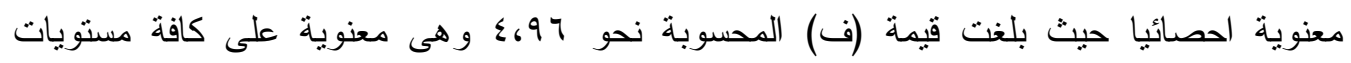

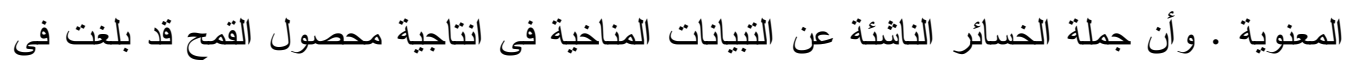

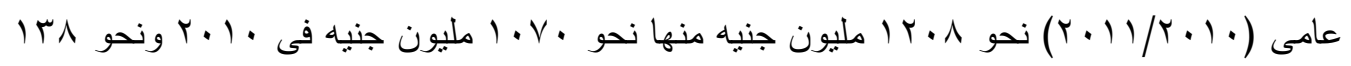

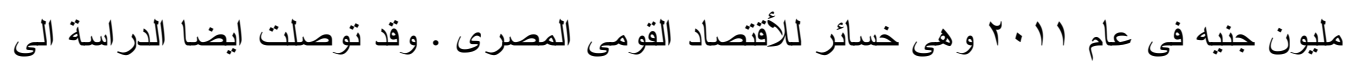

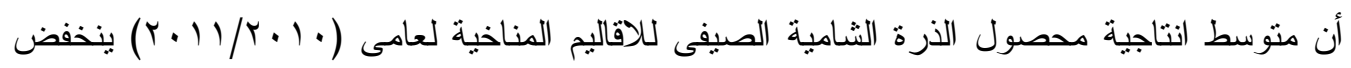
بارتفاع درجة حرارة الأقليم حيث بلغ ذلك المتوسط نحو وجس، طن طن للفدان فى اقليم شمال الدلتا

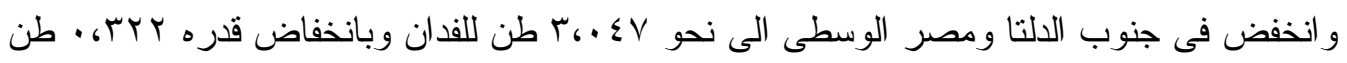

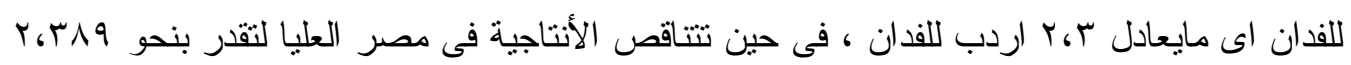

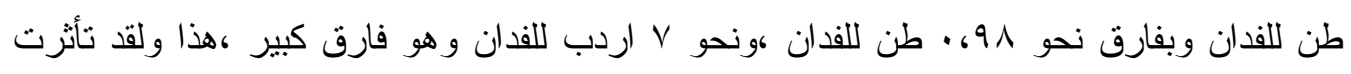

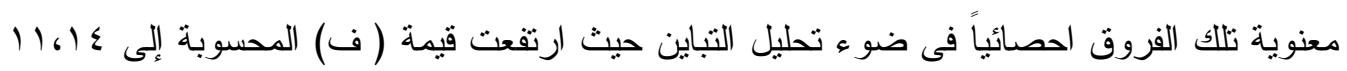
و هى معنوية على كافة مستويات المعنوية وأن جملة الخسائر الناشئة عن التبيانات المناخية الأقليمة

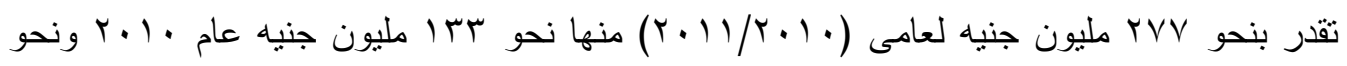

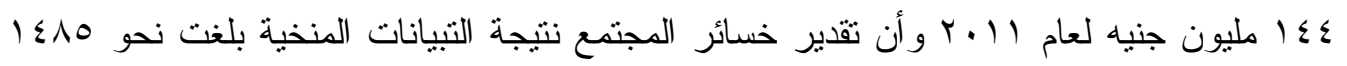
مليون جنيه مما يستدعى ضرورة التفكير فى الأستر اتيجيات و السياسات و البرامج و الأساليب المناسبة

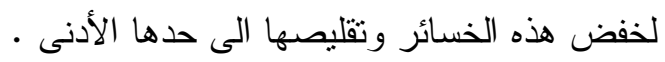




\section{هذا وتوصى الاراسة الى :}

(1) ضرورة ازدياد الوعى لخطورة الآثار السلبية لكل من الثبيانات المناخية

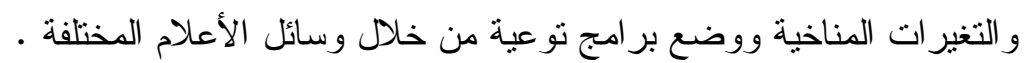

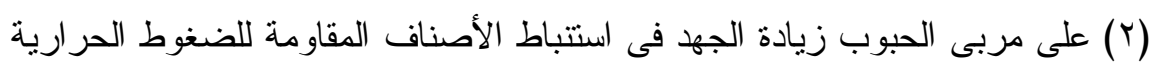

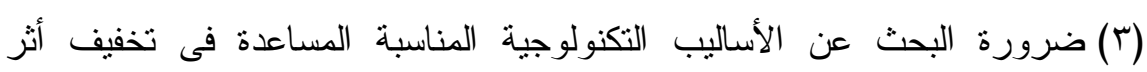

التغيرات المناخية بالاضافة الى زر اعة الأسوار الثجرية لتخفيف آثر ارتفاع

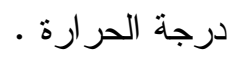

المراجع

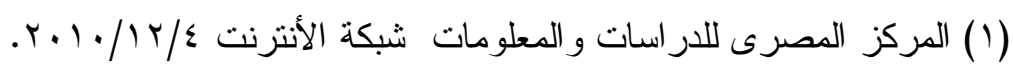

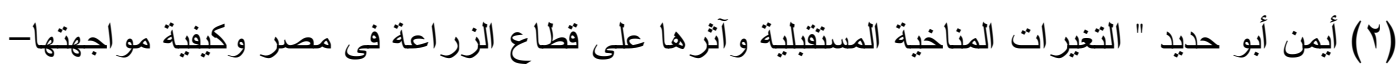

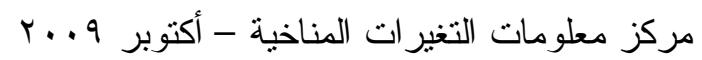

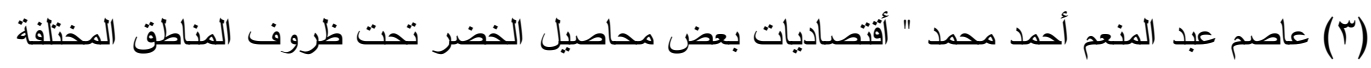

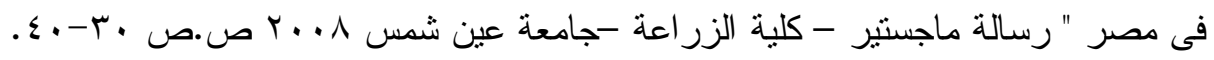

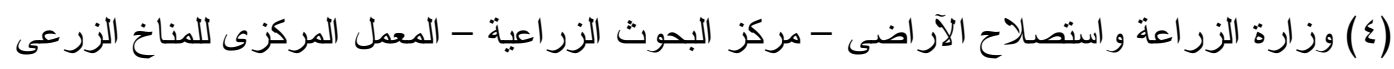

- بيانات غير منشورة .

(0) وز ارة الزر اعة وأستصلاح الآر اضى -قطاع الثئون الأقتصادية - نشر ات الاحصاءات الزر اعية -

أعداد مختلفة.

(T) وز ارة الزر اعة و أستصلاح الأر اضى - نشر ات الإدارة العامة لمكافحة الآفاتو الحشر ات- أعداد مختلفة. 